\title{
Epigenetic modifiers, 5-aza-2'-deoxycytidine and valproic acid, differentially change viability, DNA damage and gene expression in metastatic and non-metastatic colon cancer cell lines
}

\author{
Abdelmoudjib Ghecham¹, Abderrahmane Senator², Elzbieta Pawlowska³, Waffa Bouafia² and \\ Janusz Blasiak ${ }^{4}$ \\ 1 Faculty of Life Sciences, Biotechnology Laboratory of the Bioactive Molecules and Cellular Physiopathology, University of Batna 2, Batna, \\ Algeria; ${ }^{2}$ Faculty of Life Sciences, University of Batna 2, Batna, Algeria; ${ }^{3}$ Department of Orthodontics, Medical University of Lodz, Łódź, Poland; \\ 4Faculty of Biology and Environmental Protection, Department of Molecular Genetics, University of Lodz, Łódź, Poland
}

DNA methylation and histone modifications are major components of cellular epigenetic pattern determining gene expression. Cancer cells have their own epigenetic array, which can be different in cells of primary and metastatic tumors. In the work presented here, we investigated effects of $1 \mathrm{mM}$ valproic acid (VPA), a histone deacetylase inhibitor, and $0.2 \mu \mathrm{M}$ 5-aza-2'-deoxycytidine (5-aza-dC), a DNA demethylation agent, singly or in combination in two colorectal cancer cell lines: Caco-2 (nonmetastatic) and LoVo (metastatic). Cell viability, DNA damage and mRNA expression of the CDC25C (cell division cycle 25C), CDKN1A (cyclin dependent kinase inhibitor 1A) and CHEK1 (checkpoint kinase 1), SQSTM1 (p62, sequestosome 1), ULK1 (unc-51 like autophagy activating kinase 1), RELA (RELA proto-oncogene, NF-KB subunit) and TP53BP1 (tumor protein p53 binding protein 1) genes important for cell cycle regulation, autophagy and cancer progression were investigated. Both drugs induced a moderate decrease in cell viability and a significant DNA damage in both cell lines. The LoVo cells were more sensitive to VPA and combined treatment than Caco-2. The LoVo cells also showed higher expression of genes that are often associated with more aggressive tumors than the Caco-2 cells and treatment with modifiers had increased this difference. In conclusion, 5-aza-dC and VPA can induce different effects in metastatic and non-metastatic cancer cell lines and this may be important in determination of an epigenetic profile responsible for metastatic properties of cancer cells.

Key words: epigenetic modifiers; anticancer therapy; 5-Aza-dC; VPA; colorectal cancer; metastatic and non-metastatic cancer cells; DNA damage; gene expression

Received: 09 May, 2019; revised: 13 June, 2019; accepted: 13 June, 2019; available on-line: 09 July, 2019

$\checkmark$ e-mail: janusz.blasiak@biol.uni.lodz.pl

Abbreviations: 5-Aza-dC, 5-aza-2'-deoxycytidine; CDC25C, cell division cycle 25C; CDKN1A, cyclin dependent kinase inhibitor 1a; CHEK1, cell cycle checkpoint kinase 1; DNMT, DNA methyltransferase; GAPDH, glyceraldehyde-3-phosphate dehydrogenase; $\mathrm{HDACi}$, histone deacetylase inhibitor; NF-kB, nuclear factor-kappa B; RELA, nuclear factor NF-Kappa-B P65 subunit; SQSTM1, sequestosome 1 (p62); TP53BP1, tumor protein p53 binding protein 1; TSA, trichostatin A; ULK1, unc-51 like autophagy activating kinase 1 gene; VPA, valproic acid

\section{INTRODUCTION}

Malignant tumors contain a heterogeneous collection of cancer cells and this heterogeneity reflects various functions that they may play in cancer transformation (Caswell \& Swanton, 2017; Prasetyanti \& Medema, 2017). Although identification and eradication of cancer stem or stem-like cells can be an ultimate goal of cancer therapy, targeting the subpopulation of cells involved in metastasis is crucial, as metastasis is the main reason for cancer-related death (De Greef et al., 2016). Cells involved in metastasis are characterized by a different phenotype than cells that are not implicated in this process. This phenotypic specificity is determined by a specific gene expression pattern, which in turn is determined by the gene sequence and epigenetic modifications of DNA and histones, as well as activity of regulatory RNAs (Toh et al., 2017). These modifications result from mutations or/and altered expression of epigenetic enzymes and their regulators (You \& Jones, 2012). Therefore, changes in the epigenetic pattern of cancer cells may lead to the loss or acquisition of phenotypes important in cancerrelated effects, including metastasis. Determination of epigenetic pattern specific to metastasis is important for cancer prognosis and therapy, as it can be targeted to change into a pattern associated with a less-invasive phenotype or to induce cancer cell senescence or death.

Many drugs targeting proteins involved in the formation and maintenance of an epigenetic pattern have been approved in cancer therapy or are being tested in clinical trials (reviewed in (Mohammad et al., 2019)). This kind of therapy is called the epigenetic therapy. Such drugs mainly target DNA methylation and chemical modifications of histone tails, and are represented by various compounds, but likely the most widely investigated drugs are inhibitors of enzymes involved in epigenetic modifications, including DNA methyltransferases (DNMTs), histone deacetylases (HDACs) and methyltransferases, as well as BET (bromodomain and extra-terminal domain) family proteins (reviewed in (Zhao et al., 2018)).

Several drugs for epigenetic therapy, including decitabine and azacitidine (DNMT inhibitors, DNMTi), belinostat, vorinostat and romidespin (HDAC inhibitors, HDACi) have been approved as drugs for monotherapy in hematologic cancers (Taby \& Issa, 2010). Such drugs are also reported to produce a synergistic reaction with conventional anticancer drugs, targeted drugs and drugs for immunotherapy, when applied in com- 
bination (Raynal et al., 2017). In addition, a combined treatment with epigenetic drugs may result in a synergistic outcome, as shown for the first time at the end of the last century for the reactivation of tumor suppressor and other cancer-related genes after a joint action of HDACi and DNMTi (Cameron et al., 1999). Since then, many combinations of DNMTi and HDACi have been tested in both, preclinical studies and clinical trials (Bhadury et al., 2014; Fiskus et al., 2017; Fiskus et al., 2009; Juergens et al., 2011; Kirschbaum et al., 2014; Momparler et al., 2012). Cancer, similarly to other complex diseases, is presumed to be more susceptible to a combined treatment than monotherapy (Bertolini et al., 2015).

In the work presented here, we investigated the effect of two modifiers of cellular epigenetic pattern: valproic acid (VPA), an HDACi, and 5-aza-2'-deoxycytidine (5-aza-dC), a DNA demethylating agent, alone or in combination, in two colorectal cancer cell lines: Caco-2 and LoVo. Caco-2 is the colon adenocarcinoma cell line derived from primary colorectal tumor, whereas LoVo originates from colon adenocarcinoma metastatic site: the left supraclavicular region (Drewinko et al., 1979). Therefore, we assumed that we employed a cell line that represents a growing and invading, but non-metastatic tumor (Caco-2), which we called non-metastatic, and another cell line representing tumor at the stage of metastasis (LoVo), and so we called it metastatic. Although either cell line contains a great array of cells with different phenotypes, we assumed that LoVo contained more cells with a metastatic phenotype than Caco-2. Therefore, we compared the influence of epigenetic modifiers, which are used as epigenetic drugs in non-metastatic and metastatic colon cancer cell lines, assuming that their different properties are underlined, at least in part, by different epigenetic profiles of these cells. We investigated cell viability, DNA damage and expression of a panel of genes important in metabolism of cancer cells in non-metastatic and metastatic colon cancer cell lines exposed to VPA or/and 5-aza-dC. mRNA expression of the TP53BP1 (tumor protein p53 binding protein 1), CDC25C (cell division cycle $25 \mathrm{C}$ ), CDKN1A (cyclin dependent kinase inhibitor 1A) and CHEK1 (checkpoint kinase 1) genes that are involved in DNA damage response (DDR) and/ or cell cycle regulation, was assessed. Also, genes important in autophagy: SQSTM1 (p62, sequestosome 1) and ULK1 (unc-51 like autophagy activating kinase 1), as well as RELA (RELA proto-oncogene, NF- $x \mathrm{~B}$ subunit) that is involved in inflammation, immunity response, cell growth and differentiation, tumorigenesis and apoptosis were investigated.

\section{MATERIALS AND METHODS}

Chemicals. VPA and 5-aza-dC obtained from Merck (Poznan, Poland) were dissolved in water or DMSO, respectively, to prepare stock solutions kept at $-20^{\circ} \mathrm{C}$. Cell culture media DMEM (Dulbecco's modified Eagle medium) and EMEM (Eagle's minimal essential medium) were obtained from Lonza (Basel, Switzerland). Low melting point (LMP) and normal melting point (NMP) agarose, resazurin, phosphate buffered saline (PBS), fetal bovine serum (FBS), penicillin, streptomycin, DAPI (4',6-diamidino-2-phenylindole) and hydrogen peroxide were purchased from Merck. Reagents for gene expression analysis were obtained from Thermo Fisher Scientific (Waltham, MA, USA).

Cells and treatment. The Caco-2 and LoVo cell lines were obtained from ATCC (Manassas, VA, USA). Nor- mal colorectal cell line CCD841 was kindly donated by Dr. B. Szymanska (CoreLab, Medical University of Lodz, Lodz, Poland). After reaching confluence and determination of cell density and viability by trypan blue exclusion, the cells were ready to use. They were incubated at $37^{\circ} \mathrm{C}$ for $24 \mathrm{~h}$ with VPA at $1 \mathrm{mM}$ or for $72 \mathrm{~h}$ with $0.2 \mu \mathrm{M} 5$-aza-dC. In the combined exposure mode, cells were treated for $48 \mathrm{~h}$ with $0.2 \mu \mathrm{M} 5$-aza-dC and then VPA was added to a final concentration of $1 \mathrm{mM}$ and incubation proceeded for the next $24 \mathrm{~h}$. Cells that were treated for $30 \mathrm{~min}$ on ice with $15 \mathrm{mM}$ hydrogen peroxide were used as a positive control. Cell viability was determined with Resazurin Based In Vitro Toxicology Assay Kit (Merck).

Comet assay. Comet assay was performed in an alkaline version according to the procedure of Singh et al. with some modifications, as described previously (Klaude et al., 1996; Pawlowska et al., 2014; Singh et al., 1988). Briefly, a $5 \times 10^{4}$ suspension of cells in LMP agarose was spread on microscope slides precoated with NMP agarose. After lysis and denaturation, electrophoresis was run in alkaline $(\mathrm{pH}>13)$ conditions. The slides were observed at $200 \times$ magnification under an Eclipse fluorescence microscope (Nikon, Tokyo, Japan) connected with COHU 4910 digital video camera (Cohu, San Diego, CA, USA) and analyzed with Lucia-Comet V.4.51 (Laboratory Imaging, Praha, Czech Republic). A hundred randomly selected cells were chosen to assess the DNA content in the comet tail and each experiment was performed in triplicate.

Gene expression. Total RNA was extracted with RNeasy preparation Kit (Chatsworth, CA, USA). cDNA was synthesized using Thermo Scientific Maxima First Strand cDNA Synthesis Kit (Thermo Fisher Scientific). A total of 10 ng RNA were used per experiment. TaqMan ${ }^{\circledR}$ Fast Advanced Master Mix kits with specific primers (Thermo Fisher Scientific) were used to measure mRNA levels of the CDC25C (probe ID Hs00156411_m1), CDKN1A (Hs00355782_ml), CHEK1 (Hs00967510_g1), RELA (Hs01042014_m1), SQSTM1 (Hs01061917_g1), TP53BP1 (Hs00996827_m1) and ULK1 (Hs00177504_ m1) genes. The gene encoding glyceraldehyde-3-phosphate dehydrogenase (GAPDH) was used as an internal control. mRNA expression was related to that measured in normal colorectal CCD841 cells. These cells were used only as a reference and were not exposed to any epigenetic modifier. Real time quantitative PCR (RT-qP$\mathrm{CR}$ ) was run at $95^{\circ} \mathrm{C}$ for $2 \mathrm{~min}$, followed by 40 cycles at $95^{\circ} \mathrm{C}$ for $1 \mathrm{~s}$ and $60^{\circ} \mathrm{C}$ for $20 \mathrm{~s}$. Samples were run in duplicate. Applied Biosystems 7900HT Fast Real-Time PCR System machine was used. All data were analyzed by Sequence Detection System 2.0 (Thermo Fisher Scientific). Relative expression was calculated according to the $2^{-\Delta \Delta \mathrm{ct}}$ method and presented as the fold change ratio to CCD841 cells (Livak \& Schmittgen, 2001).

Data analysis. Statistical analyses were performed with the SigmaPlot v. 12.5 software (Systat Software, Inc., San Jose, CA, USA). Statistical significance was determined by performing one-way ANOVA, with Tukey post-hoc multiple comparison (cell viability, DNA damage) or Student t-test (gene expression).

\section{RESULTS}

\section{Cell viability}

5-Aza-dC and VPA, both singly and in combination, evoked a moderate decrease in the viability of both cell 


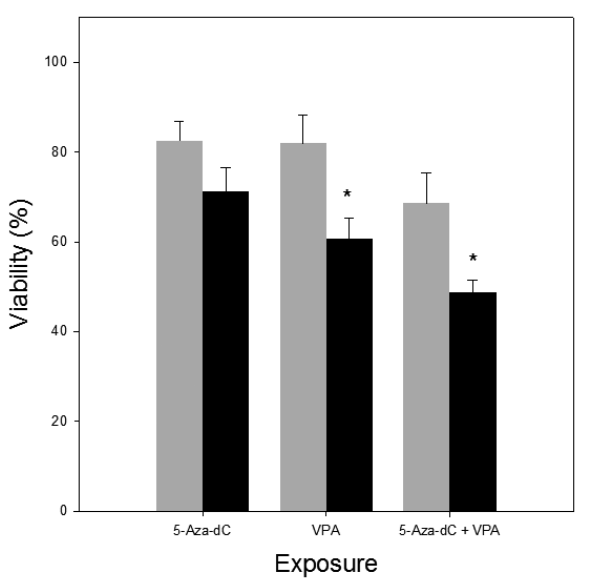

Figure 1. Relative viability of colorectal cancer Caco-2 (gray) and LoVo (black) cells exposed at $37^{\circ} \mathrm{C}$ to $1 \mathrm{mM} 5$-aza-2'-deoxycytidine (5-Aza-dC, $72 \mathrm{~h}$ ) and $0.2 \mu \mathrm{M}$ valproic acid (VPA, $24 \mathrm{~h}$ ) singly or in combination, as evaluated by the resazurin based assay and expressed as percentage of the viability of control (nonexposed) cells.

Each point is mean of six independent experiments and error bars represent S.E.M.; ${ }^{*} p<0.05$ for comparison between LoVo and Caco-2.

lines (Fig. 1). That decrease was more pronounced for LoVo than Caco-2 cells after exposure to VPA and combined treatment ( $p<0.05$ in both cases). A 30-min exposure on ice to $\mathrm{H}_{2} \mathrm{O}_{2}$ at $15 \mathrm{mM}$ (positive control) resulted in about 50\% decrease in cell viability in both cell lines (results not shown). We presumed that the conditions of incubation with the epigenetic modifiers preserve the viability of the cells to study DNA damage and gene expression independently of their cytotoxicity.

\section{DNA damage}

Both modifiers induced a significant DNA damage in both, the Caco-2 and LoVo cells, expressed as an increase in the DNA content in the tail of comets in the alkaline comet assay (Fig. 2). The extent of DNA damage in the Lovo cells was significantly $(p<0.05)$ higher

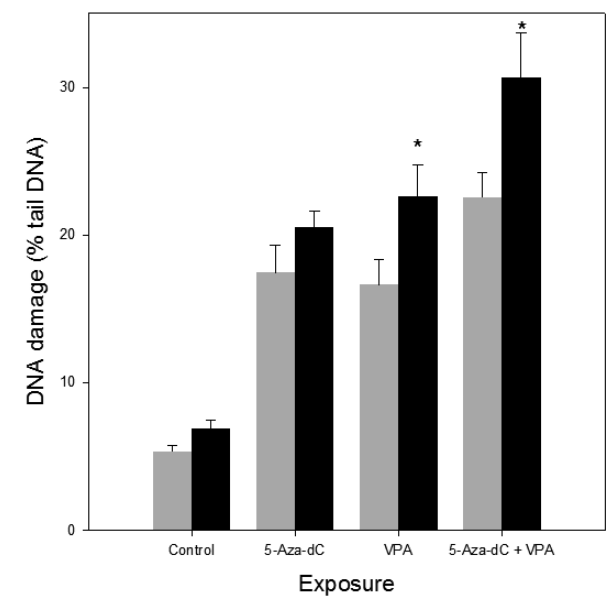

Figure 2. DNA damage in colorectal cancer Caco-2 (gray) and

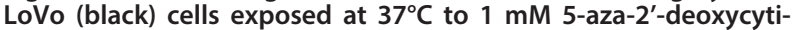
dine (5-Aza-dC, $72 \mathrm{~h}$ ) and $0.2 \mu \mathrm{M}$ valproic acid (VPA, $24 \mathrm{~h}$ ) singly or in combination, evaluated by the alkaline version of the comet assay and expressed as DNA percentage in the tail of comets. The mean value for one hundred cells analyzed in each treatment in three independent experiments is presented; error bars represent S.E.M.; ${ }^{*} p<0.05$ for comparison between LoVo and Caco-2. than in the Caco-2 cells, when the cells were incubated with VPA or both modifiers.

\section{Gene expression}

We observed pronounced differences in the expression of almost all genes between the non-metastatic Caco-2 and the metastatic LoVo control (unexposed) cells (Fig. 3). Exposure to 5-aza-dC or VPA increased these differences, especially in case of the combined treatment. For most genes, LoVo cells showed a greater level of mRNA expression than Caco-2 cells, and in the case of the CDKN1A and SQSTM1 genes, their expression in LoVo cells exceeded that observed in Caco-2 cells by many folds, particularly in case of the combined treatment. However, mRNA expression of the CHEK1 gene was lower in the LoVo than Caco-2 cells for all modes of incubation. In general, expression of all genes

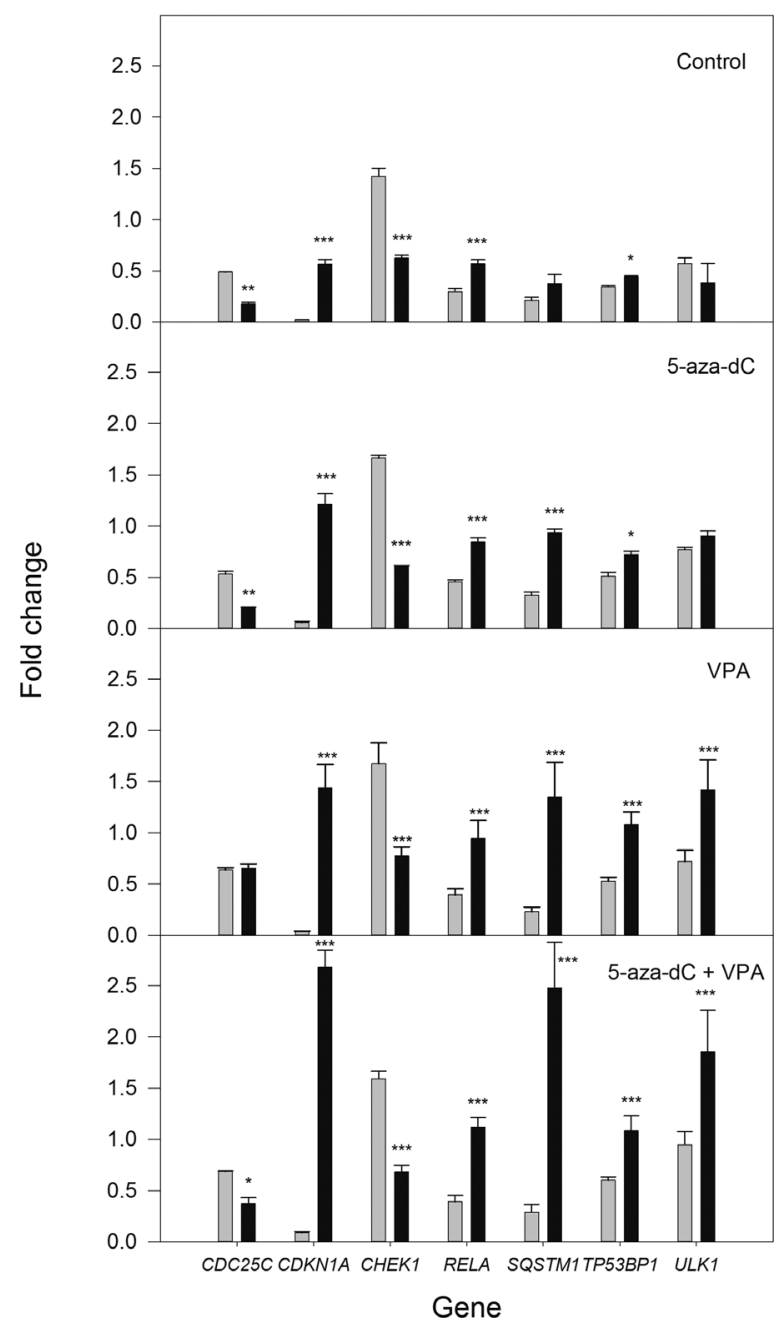

Figure 3. Relative expression of the $C D C 25 C$ (cell division cycle 25C), CDKN1A (cyclin dependent kinase inhibitor 1A), CHEK1 (checkpoint kinase 1), RELA (RELA proto-oncogene, NF-KB subunit), SQSTM1 (p62, sequestosome 1), TP53BP1 (tumor protein p53 binding protein 1) and ULK1 (unc-51 like autophagy activating kinase 1) genes in colorectal cancer Caco-2 (gray) and LoVo (black) cells exposed at $37^{\circ} \mathrm{C}$ to $1 \mathrm{mM} 5$-aza-2'-deoxycytidine $(5-A z a-d C, 72 \mathrm{~h}$ ) and $0.2 \mu \mathrm{M}$ valproic acid (VPA, $24 \mathrm{~h}$ ), singly or in combination.

The mRNA expression was determined by real time quantitative PCR and is presented as fold change relative to normal colorectal CCD841 cells. Expression of each gene was assessed in duplicate. Error bars represent S.D., $\mathrm{n}=2$ for each gene; ${ }^{*} p<0.05,{ }^{* *} p<0.01$, ${ }^{* * *} p<0.001$ for comparison between LoVo and Caco-2. 
in the Caco-2 cells did not show a pronounced change under any treatment.

\section{DISCUSSION}

Metastasis is still the main reason for cancer-related death and it determines the line in cancer progression which is associated with fatal prognosis once crossed. Progress in therapy of metastatic cancer is much slower than in the general anticancer therapy, and in fact such therapy is usually only palliative to help to control and reduce the cancer-associated syndromes (Lobbezoo et al., 2016). Therefore, studies on molecular aspects of the process of metastasis are justified. Metastatic cancer cells must have different properties than the rest of the tumor mass to invade borders of the surrounding tissues, migrate with bloodstream and colonize distant organs (van Zijl et al., 2011). These properties are determined, at least in part, by mutations and changes in epigenetic pattern in some genes (Macaluso et al., 2003). Therefore, search for modifiers of epigenetic pattern that may be important for metastasis is warranted.

Many modifiers of cellular epigenetic pattern are tested in preclinical research and clinical trials. In most cases, a single substance is investigated, but accumulating evidence suggests that combined treatment may be more effective due to positive synergistic drug interactions (Raynal et al., 2017). 5-aza-dC (azacitidine) proved to be effective in combination with entinostat, an HDAC1/3 inhibitor in a phase I/II trial in patients with recurrent metastatic non-small cell lung cancer (Juergens et al., 2011). Combined treatment leads to lowering of concentrations of individual compounds that are otherwise toxic to normal cells. Combined therapy may be carried out in a concurrent or sequential mode. Kirschbaum and coworkers (Kirschbaum et al., 2014) had shown that concurrent therapy with vorinostat and decitabine was more effective than its sequential administration in patients with acute myeloid leukemia (AML) or myelodisplastic syndrome in phase 1 trial. Similarly, Fiskus and coworkers (Fiskus et al., 2009) had shown that combined treatment with the $S$-adenosylhomocysteine hydrolase inhibitor 3-deazaneplanocin, an inhibitor of histone methyltransferase, and panobinostat, a non-selective histone deacetylase inhibitor proved to be effective in selective epigenetic therapy against AML cells.

Combined therapy with DNMTi and HDACi seems to be especially justified as hypermethylated DNA combines with transcriptionally silent chromatin, typified by the presence of deacetylated histones. This combination is mediated by the recruitment of methylCpG-binding proteins (MBDs) that can complex with HDACs (Rountree et al., 2001). Moreover, the link between HDAC activity and DNA methylation is essential for transcriptional silencing of tumor suppressor genes (Kondo et al., 2003). Moreover, this link has been recently recognized as significant for many other genes important for cancer development, including genes whose products are involved in DNA repair, cell cycle regulation, apoptosis, differentiation, cell-cell interaction and others, including some genes investigated in the present work (Kondo, 2009). However, not only canonical synergy may matter, as even an additive effect or just a significant increase can bring a therapeutic benefit. In our study, we did not detect any synergy between 5-aza-dC and VPA, but we showed that cell viability was more efficiently decreased in the case of combined treatment as compared with either compound used singly. The same concerns an increase in the extent of DNA damage. Whether the difference between combined and individual treatments could be of therapeutic significance is to be established.

We observed an induction of DNA damage in both cell lines by VPA and the combined treatment. Although both chemicals address epigenetic pattern, they are not limited to that target. Moreover, changes in epigenetic pattern of some genes, e.g. DNA maintenance genes, may result in DNA damage induction. Tung and Winn had observed an increase in DNA damage in mice after administration of teratogenic doses of VPA (Tung \& Winn, 2011). This effect could be indirect as it was associated with activation of apoptosis and inhibition of cell cycle. Similar results were obtained earlier by Schulpis et al. who had shown increased levels of 8-oxoG in the serum of children on VPA monotherapy (Schulpis et al., 2006). It was hypothesized that VPA induced free radicals through impairment of the liver functions. Also, 5 -aza-dC was reported to induce DNA damage (Hollenbach et al., 2010; Jung et al., 2007; Khan et al., 2012; Sampath et al., 2003). DNA-damaging effects induced by VPA and 5-aza-dC in cancer cells may support their anticancer action.

We observed a difference in the expression of genes that are essential for cancer cell metabolism in metastatic and non-metastatic cell lines. The action of epigenetic modifiers increased these differences with the greatest effects observed for combined exposure. In general, modifiers had increased expression of majority of the genes, especially in the LoVo cells, which is in agreement with general action of these compounds, as 5 -aza-dC may demethylate promoters of genes, increasing their accessibility for transcription factors. VPA, as an HDAC inhibitor, may preserve an open configuration of chromatin, which favors gene expression. Changes in histone modifications occurring in the chromatin in case of genes that show no marked change in DNA methylation may also indirectly affect gene expression (Seelan et al., 2018). Suzuki and coworkers (Suzuki et al., 2002) suggested that Trichostatin A (TSA), an HDACi, could reactivate silenced genes with unmethylated promoters, while genes with hypermethylated promoters required both, 5-aza-dC and TSA.

RELA, a product of the RELA protooncogene, plays an important role in the activation of genes involved in inflammation and the immune response, and it is implicated in epithelial-mesenchymal transition in cancer and metastasis (Huber et al., 2004; Julien et al., 2007). We observed higher RELA expression in the LoVo than Caco-2 cells, and treatment with the modifiers had increased RELA expression, but only in the LoVo cells. Therefore, its enhanced expression may be specific for metastatic cells. High expression of RELA was positively correlated with lymph node metastasis of nasopharyngeal carcinoma (Hu et al., 2010). It was also associated with invasive phenotype in breast cancer (Wang et al., 2007). RELA can contribute to cancer development by inducing transcription of $B c / 2$ and stimulating angiogenesis through activation of inflammatory cytokines (Basseres \& Baldwin, 2006; Naugler \& Karin, 2008).

CHEK1, an essential regulator of the G2/M checkpoint and DNA damage response, was overexpressed in metastasis of liposarcoma (Gobble et al., 2011). CHEK1 expression was often more correlated with aggressive tumors (Verlinden et al., 2007; Yao et al., 2010). However, we observed a decreased expression of CHEK1 in the LoVo cells as compared with the Caco-2 cells, but CHEK1 plays so many diverse functions in both, normal and cancer cells, that its role in the process of metasta- 
sis may be quite complex and our experimental design is apparently not sufficient to assess that role.

Our work has several limitations. We did not check whether 5-aza-dC and VPA exerted their action of epigenetics modifiers in the Caco-2 and LoVo cells, as it was shown many times elsewhere. Strey and others (Strey et al., 2011) had shown that VPA at 1 or $5 \mathrm{mM}$ increased acetylation of $\mathrm{H} 3$ and $\mathrm{H} 4$ histones in the Caco-2 cells. In turn, Papi and others (Papi et al., 2012) had shown that VPA at 1 or $3 \mathrm{mM}$ inhibited HDAC1 in the LoVo cells. Habano et al. had shown a DNA demethylating action of 5 -aza-dC in the promoter of the pregnane $X$ receptor gene in both cell lines (Habano et al., 2011). We focused on cancer cells with no parallel study on normal cells. Adverse side effects of anticancer drugs in normal cells are one of the most, if not the most, serious obstacles in cancer therapy and they should not surpass beneficial effects for cancer cells. However, safety of 5-aza-dC and VPA was tested in several clinical trials (Elshafay et al., 2019; Schuh et al., 2017). In our gene expression analysis we included genes which can be important for basic cellular processes whose deregulation may contribute to cancer transformation. We did not include genes that are suggested to play an essential role in colorectal cancer metastasis, as they have not been unequivocally identified and there are too many candidates to be included in such analysis. For instance, Al-Temaini et al. had observed that 42 genes were associated with metastatic relapse, short disease-free or overall survival and/or epithelial to mesenchymal transition in stage II colorectal cancer (Al-Temaimi et al., 2016). All of them might be active in the metastatic relapse, but due to gene ontology they can be classified into genes involved in growth regulation, DNA maintenance, metabolism regulation and signal transduction, similarly to genes analyzed in the present work. We used two cell lines originating from different individuals, but we did not consider potentially different genetic background. Therefore, difference in gene expression might result from different spectrum of mutations that might determine different response to epigenetic modifiers. The metastatic LoVo cells were taken from secondary tumor and there is no guarantee that they still possessed properties which enabled them to metastasize.

In conclusion, we observed different reactions of metastatic and non-metastatic colon cancer cells to two epigenetic modifiers in cell viability, DNA damage and especially in the expression of genes important for metabolism of cancer cells. These results can contribute to identification of cellular properties responsible for metastasis.

\section{Conflict of interest statement}

The authors do not declare any conflict of interest associated with this manuscript.

\section{REFERENCES}

Al-Temaimi RA, Tan TZ, Marafie MJ, Thiery JP, Quirke P, Al-Mulla F (2016) Identification of 42 genes linked to stage II colorectal cancer metastatic relapse. Int J Mol Sci 17: 598. https://doi.org/10.3390/ ijms 17050598

Basseres DS, Baldwin AS (2006) Nuclear factor-kappab and inhibitor of kappab kinase pathways in oncogenic initiation and progression. Oncogene 25: 6817-6830. https://doi.org/10.1038/sj.onc.1209942

Bertolini F, Sukhatme VP, Bouche G (2015) Drug repurposing in oncology - patient and health systems opportunities. Nat Rev Clin Oncol 12: 732-742. https:// doi.org/10.1038/nrclinonc.2015.169

Bhadury J, Nilsson LM, Muralidharan SV, Green LC, Li Z, Gesner EM, Hansen HC, Keller UB, McLure KG, Nilsson JA (2014)
Bet and hdac inhibitors induce similar genes and biological effects and synergize to kill in myc-induced murine lymphoma. Proc Natl Acad Sci U S A 111: E2721-E2730. https://doi.org/10.1073/ pnas. 1406722111

Cameron EE, Bachman KE, Myohanen S, Herman JG, Baylin SB (1999) Synergy of demethylation and histone deacetylase inhibition in the re-expression of genes silenced in cancer. Nat Genet 21: 103107. https://doi.org/10.1038/5047

Caswell DR, Swanton C (2017) The role of tumour heterogeneity and clonal cooperativity in metastasis, immune evasion and clinical outcome. BMC Med 15: 133. doi:10.1186/s12916-017-0900-y

De Greef K, Rolfo C, Russo A, Chapelle T, Bronte G, Passiglia F, Coelho A, Papadimitriou K, Peeters M (2016) Multisciplinary management of patients with liver metastasis from colorectal cancer. World J Gastroenterol 22: 7215-7225. https://doi.org/10.3748/wig. v22.i32.7215

Drewinko B, Barlogie B, Freireich EJ (1979) Response of exponentially growing, stationary-phase, and synchronized cultured human colon carcinoma cells to treatment with nitrosourea derivatives. Cancer Res 39: 2630-2636.

Elshafay A, Hieu TH, Doheim MF, Kassem MAM, MF EL, Holloway SK, Abo-Elghar H, Hirayama K, Huy NT (2019) Efficacy and safety of valproic acid for spinal muscular atrophy: A systematic review and meta-analysis. CNS Drugs 33: 239-250. https://doi. org/10.1007/s40263-019-00606-6

Fiskus W, Sharma S, Shah B, Portier BP, Devaraj SGT, Liu K, Iyer SP, Bearss D, Bhalla KN (2017) Highly effective combination of lsd1 $(\mathrm{kdm} 1 \mathrm{a})$ antagonist and pan-histone deacetylase inhibitor against human aml cells. Leukemia 31: 1658. https://doi.org/10.1038/ leu.2017.77

Fiskus W, Wang Y, Sreekumar A, Buckley KM, Shi H, Jillella A, Ustun C, Rao R, Fernandez P, Chen J, Balusu R, Koul S, Atadja P, Marquez VE, Bhalla KN (2009) Combined epigenetic therapy with the histone methyltransferase ezh2 inhibitor 3-deazaneplanocin $\mathrm{a}$ and the histone deacetylase inhibitor panobinostat against human aml cells. Blood 114: 2733-2743. https://doi.org/10.1182/ blood-2009-03-213496

Gobble RM, Qin LX, Brill ER, Angeles CV, Ugras S, O'Connor RB, Moraco NH, Decarolis PL, Antonescu C, Singer S (2011) Expression profiling of liposarcoma yields a multigene predictor of patient outcome and identifies genes that contribute to liposarcomagenesis. Cancer Res 71: 2697-2705. https://doi.org/10.1158/0008-5472.Can$10-3588$

Habano W, Gamo T, Terashima J, Sugai T, Otsuka K, Wakabayashi $G$, Ozawa S (2011) Involvement of promoter methylation in the regulation of pregnane $\mathrm{x}$ receptor in colon cancer cells. BMC Cancer 11: 81. https://doi.org/10.1186/1471-2407-11-81

Hollenbach PW, Nguyen AN, Brady H, Williams M, Ning Y, Richard N, Krushel L, Aukerman SL, Heise C, MacBeth KJ (2010) A comparison of azacitidine and decitabine activities in acute myeloid leukemia cell lines. PLoS One 5: e9001. https://doi.org/10.1371/ journal.pone.0009001

Hu X, Tang J, Pan J, Wu G (2010) Study of the expression of nuclear factor-kappa b, matrix metalloproteinase- $3,-9$ on nasopharyngeal carcinoma and their clinical significance. Lin Chung Er Bi Yan Hou Tou Jing Wai Ke Za Zhi 24: 678-682

Huber MA, Azoitei N, Baumann B, Grunert S, Sommer A, Pehamberger H, Kraut N, Beug H, Wirth T (2004) NF-kappa b is essential for epithelial-mesenchymal transition and metastasis in a model of breast cancer progression. J Clin Invest 114: 569-581. https://doi. org $/ 10.1172 /$ jci 21358

Juergens RA, Wrangle J, Vendetti FP, Murphy SC, Zhao M, Coleman B, Sebree R, Rodgers K, Hooker CM, Franco N, Lee B, Tsai S, Delgado IE, Rudek MA, Belinsky SA, Herman JG, Baylin SB, Brock MV, Rudin CM (2011) Combination epigenetic therapy has efficacy in patients with refractory advanced non-small cell lung cancer. Cancer Discov 1: 598-607. https://doi.org/10.1158/21598290.Cd-11-0214

Julien S, Puig I, Caretti E, Bonaventure J, Nelles L, van Roy F, Dargemont C, de Herreros AG, Bellacosa A, Larue L (2007) Activation of NF-kappa b by akt upregulates snail expression and induces epithelium mesenchyme transition. Oncogene 26: 7445-7456. https:// doi.org/10.1038/sj.onc.1210546

Jung Y, Park J, Kim TY, Park JH, Jong HS, Im SA, Robertson KD, Bang YJ, Kim TY (2007) Potential advantages of DNA methyltransferase 1 (dnmt1)-targeted inhibition for cancer therapy. J Mol Med Berl) 85: 1137-1148. https://doi.org/10.1007/s00109-007-0216-z

Khan C, Pathe N, Fazal S, Lister J, Rossetti JM (2012) Azacitidine in the management of patients with myelodysplastic syndromes. Therapeutic advances in hematology 3: 355-373. https://doi. $\operatorname{org} / 10.1177 / 2040620712464882$

Kirschbaum M, Gojo I, Goldberg SL, Bredeson C, Kujawski LA, Yang A, Marks P, Frankel P, Sun X, Tosolini A, Eid JE, Lubiniecki GM, Issa JP (2014) A phase 1 clinical trial of vorinostat in combination with decitabine in patients with acute myeloid leukaemia or my- 
elodysplastic syndrome. Br J Haematol 167: 185-193. https://doi. org/10.1111/bjh.13016

Klaude M, Eriksson S, Nygren J, Ahnstrom G (1996) The comet assay: Mechanisms and technical considerations. Mutat Res 363: 89-96

Kondo Y (2009) Epigenetic cross-talk between DNA methylation and histone modifications in human cancers. Yonsei Med J 50: 455-463. https://doi.org/10.3349/ymj.2009.50.4.455

Kondo Y, Shen L, Issa J-PJ (2003) Critical role of histone methylation in tumor suppressor gene silencing in colorectal cancer. Mol Cell Biol 23: 206-215. https://doi.org/10.1128/MCB.23.1.206-215.2003

Livak KJ, Schmittgen TD (2001) Analysis of relative gene expression data using real-time quantitative per and the 2(-delta delta $\mathrm{c}(\mathrm{t})$ ) method. Methods 25: 402-408. https://doi.org/10.1006/ meth.2001.1262

Lobbezoo DJ, van Kampen RJ, Voogd AC, Dercksen MW, van den Berkmortel F, Smilde TJ, van de Wouw AJ, Peters FP, van Riel JM, Peters NA, de Boer M, Peer PG, Tjan-Heijnen VC (2016) In real life, one-quarter of patients with hormone receptor-positive metastatic breast cancer receive chemotherapy as initial palliative therapy: A study of the southeast netherlands breast cancer consortium. Ann Oncol 27: 256-262. https://doi.org/10.1093/annonc/mdv544

Macaluso M, Paggi MG, Giordano A (2003) Genetic and epigenetic alterations as hallmarks of the intricate road to cancer. Oncogene 22: 6472-6478. https://doi.org/10.1038/sj.onc.1206955

Mohammad HP, Barbash O, Creasy CL (2019) Targeting epigenetic modifications in cancer therapy: Erasing the roadmap to cancer. Nat Med 25: 403-418. https://doi.org/10.1038/s41591-019-0376-8

Momparler RL, Idaghdour Y, Marquez VE, Momparler LF (2012) Synergistic antileukemic action of a combination of inhibitors of DNA methylation and histone methylation. Leuk Res 36: 1049-1054. https://doi.org/10.1016/j.leukres.2012.03.001

Naugler WE, Karin M (2008) Nf-kappab and cancer-identifying targets and mechanisms. Curr Opin Genet Dev 18: 19-26. https://doi. org/10.1016/j.gde.2008.01.020

Papi A, Ferreri AM, Guerra F, Orlandi M (2012) Anti-invasive effects and proapoptotic activity induction by the rexinoid iif and valproic acid in combination on colon cancer cell lines. Anticancer Res 32: 2855-2862

Pawlowska E, Wysokinski D, Tokarz P, Piastowska-Ciesielska A, Szczepanska J, Blasiak J (2014) Dexamethasone and 1,25-dihydroxyvitamin d3 reduce oxidative stress-related DNA damage in differentiating osteoblasts. Int J Mol Sci 15: 16649-16664. https://doi. org/10.3390/iims150916649

Prasetyanti PR, Medema JP (2017) Intra-tumor heterogeneity from a cancer stem cell perspective. Mol Cancer 16: 41. https://doi. org/10.1186/s12943-017-0600-4

Raynal NJ, Da Costa EM, Lee JT, Gharibyan V, Ahmed S, Zhang H, Sato T, Malouf GG, Issa JJ (2017) Repositioning fda-approved drugs in combination with epigenetic drugs to reprogram colon cancer epigenome. Mol Cancer Ther 16: 397-407. https://doi. org/10.1158/1535-7163.Mct-16-0588

Rountree MR, Bachman KE, Herman JG, Baylin SB (2001) DNA methylation, chromatin inheritance, and cancer. Oncogene 20: 31563165. https://doi.org/10.1038/sj.onc.1204339

Sampath D, Rao VA, Plunkett W (2003) Mechanisms of apoptosis induction by nucleoside analogs. Oncogene 22: 9063-9074. https://doi. org/10.1038/sj.onc.1207229

Schuh AC, Dohner H, Pleyer L, Seymour JF, Fenaux P, Dombret H (2017) Azacitidine in adult patients with acute myeloid leukemia.
Crit Rev Oncol Hematol 116: 159-177. https://doi.org/10.1016/i.critrevonc.2017.05.010

Schulpis KH, Lazaropoulou C, Regoutas S, Karikas GA, Margeli A, Tsakiris S, Papassotiriou I (2006) Valproic acid monotherapy induces DNA oxidative damage. Toxicology 217: 228-232. https://doi. org/10.1016/j.tox.2005.10.004

Seelan RS, Mukhopadhyay P, Pisano MM, Greene RM (2018) Effects of 5-aza-2'-deoxycytidine (decitabine) on gene expression. Drug $\mathrm{Me}$ tab Rev 50: 193-207. https://doi.org/10.1080/03602532.2018.14374 46

Singh NP, McCoy MT, Tice RR, Schneider EL (1988) A simple technique for quantitation of low levels of DNA damage in individual cells. Exp Cell Res 175: 184-191

Strey CW, Schamell L, Oppermann E, Haferkamp A, Bechstein WO, Blaheta RA (2011) Valproate inhibits colon cancer growth through cell cycle modification in vivo and in vitro. Exp Ther Med 2: 301-307. https://doi.org/10.3892/etm.2011.202

Suzuki H, Gabrielson E, Chen W, Anbazhagan R, van Engeland M, Weijenberg MP, Herman JG, Baylin SB (2002) A genomic screen for genes upregulated by demethylation and histone deacetylase inhibition in human colorectal cancer. Nat Genet 31: 141-149. https:// doi.org/10.1038/ng892

Taby R, Issa JP (2010) Cancer epigenetics. CA Cancer J Clin 60: 376392. https://doi.org/10.3322/caac.20085

Toh TB, Lim JJ, Chow EK (2017) Epigenetics in cancer stem cells. Mol Cancer 16: 29. https:/ /doi.org/10.1186/s12943-017-0596-9

Tung EWY, Winn LM (2011) Valproic acid-induced DNA damage increases embryonic p27kip1 and caspase-3 expression: A mechanism for valproic-acid induced neural tube defects. Reprod Toxicol 32: 255260. https://doi.org/https://doi.org/10.1016/j.reprotox.2011.05.020

van Zijl F, Krupitza G, Mikulits W (2011) Initial steps of metastasis: Cell invasion and endothelial transmigration. Mutat Res 728: 23-34. https://doi.org/10.1016/j.mrrev.2011.05.002

Verlinden L, Vanden Bempt I, Eelen G, Drijkoningen M, Verlinden I, Marchal K, De Wolf-Peeters C, Christiaens MR, Michiels L, Bouillon R, Verstuyf A (2007) The e2f-regulated gene chk1 is highly expressed in triple-negative estrogen receptor/progesterone receptor /her-2 breast carcinomas. Cancer Res 67: 6574-6581. https://doi. org $/ 10.1158 / 0008-5472$.Can-06-3545

Wang X, Belguise K, Kersual N, Kirsch KH, Mineva ND, Galtier F, Chalbos D, Sonenshein GE (2007) Oestrogen signalling inhibits invasive phenotype by repressing relb and its target bcl2. Nat Cell Biol 9: 470-478. https://doi.org/10.1038/ncb1559

Yao H, Yang Z, Li Y (2010) [expression of checkpoint kinase 1 and polo-like kinase 1 and its clinicopathological significance in benign and malignant lesions of the stomach]. Zhong Nan Da Xue Xue Bao Yi Xue Ban 35: 1080-1084. https://doi.org/10.3969/j.issn.16727347.2010.10.008

You JS, Jones PA (2012) Cancer genetics and epigenetics: Two sides of the same coin? Cancer Cell 22: 9-20. https://doi.org/10.1016/j. ccr.2012.06.008

Zhao L, Duan YT, Lu P, Zhang ZJ, Zheng XK, Wang JL, Feng WS (2018) Epigenetic targets and their inhibitors in cancer therapy. Curr Top Med Chem 18: 2395-2419. https://doi.org/10.2174/1568026619 666181224095449 